\title{
Primary structure, partial purification and regulation of key enzymes of the acetyl cycle of arginine biosynthesis in Bacillus stearothermophilus: dual function of ornithine acetyltransferase.
}

\author{
Vehary Sakanyan, ${ }^{1 \dagger}$ Daniel Charlier, ${ }^{2}$ Christianne Legrain, ${ }^{2}$ Anahit Kochikyan, ${ }^{1}$ \\ Igor Mett, ${ }^{1}$ ANDré PiÉRARD ${ }^{2,3}$ and Nicolas GlanSDORFF ${ }^{2,4 *}$ \\ ${ }^{1}$ Pharmagen, Knunyants Street 4, Yerevan 375010, Republic of Armenia \\ ${ }^{2}$ Research Institute, CERIA-COOVI, 1 avenue Emile Gryson, B-1070 Brussels, Belgium \\ ${ }^{3}$ Laboratoire de Microbiologie, Université Libre de Bruxelles and ${ }^{4}$ Laboratorium voor Erfelijkheidsleer en \\ Microbiologie, Vrije Universiteit Brussel, Brussels, Belgium
}

(Received 7 August 1992; revised 6 November 1992; accepted 1 December 1992)

\begin{abstract}
A $3.4 \mathrm{~kb} E c o$ RI fragment, cloned in $E$. coli, that carries part of a cluster of genes encoding arginine biosynthetic functions of the thermophilic bacterium Bacillus stearothermophilus, was sequenced on both strands. The sequence consists of a truncated $\arg C$ gene, an $\arg J$ region encoding a polypeptide with both $N$-acetylglutamate synthase and ornithine acetyltransferase activities, the $\arg B$ gene and the $N$-terminal part of $\arg D$. The $\arg B$ gene encodes a 258-amino-acid polypeptide with a deduced $M_{\mathrm{r}}$ of 26918. A very high and thermostable $N$ acetylglutamate 5-phosphotransferase activity was detected in extracts of $E$. coli argB mutants transformed with the $3.4 \mathrm{~kb}$ fragment on a plasmid. A polypeptide band of $M_{\mathrm{r}} 27000$ was detected by SDS-PAGE of heat-treated extract from such a strain. Both $\mathrm{N}$-acetylglutamate synthase and ornithine acetyltransferase are encoded by the same $1290 \mathrm{bp}$ open reading frame. The deduced sequence of 410 amino acids corresponds to a peptide of $M_{\mathrm{r}}$ 43349. The subcloned $B$. stearothermophilus arg $J$ can complement a double $\arg A$ arg $E E$. coli mutant to prototrophy. Gel-filtration of a heat-treated extract of the complemented double mutant $E$. coli host showed that $N$-acetylglutamate synthase and ornithine acetyltransferase activities co-elute in a single peak corresponding to $M_{\text {r }}$ 110000. Both activities were also heat-inactivated at the same temperature and strongly inhibited by ornithine. These results suggest that both activities can be ascribed to a single protein.
\end{abstract}

\section{Introduction}

Two pathways are known for the de novo synthesis of ornithine, a precursor of arginine. In the so-called 'linear' pathway, $N^{2}$-acetyl-L-ornithine is converted into ornithine and acetate by $N^{2}$-acetyl-L-ornithine aminohydrolase (acetylornithinase; EC 3.5.1.16; genetic symbol $\arg E$ ). This route is characteristic of Enterobacteriaceae among eubacteria, and of Sulfolobus solfataricus among archaeobacteria (see Van de Casteele et al., 1990). In the so-called 'cyclic' pathway, however,

*Author for correspondence. Tel. 25267270 ; fax 25267042.

$\uparrow$ Present address: Laboratoire de Biologie et Biotechnologie Végétale, Université de Nantes, F-44072 Nantes Cedex 03, France.

The nucleotide sequence data reported in this paper have been submitted to GenBank and have been assigned the accession number L06036. the acetyl group of $N^{2}$-acetyl-L-ornithine is recycled through acetylation of glutamate to produce $N^{2}$-acetyl-Lglutamate, an earlier precursor of ornithine; this transacetylation is catalysed by ornithine acetyltransferase ( $N^{2}$-acetyl-L-ornithine: L-glutamate $N$-acetyl-transferase; EC 2.3.1.35; genetic symbol $\arg J$ ). The cyclic route is used by all other prokaryotes investigated up to now, including the genus Bacillus (Sakanyan et al., 1992) and eukaryotic microbes (see Cunin et al., 1986; Davis et al., 1986). $N$-Acetylglutamate synthase (acetyl-CoA:Lglutamate $N$-acetyltransferase; EC 2.3.1.1; genetic symbol $\arg A$ ) is common to both pathways but, in the cyclic one, plays a purely anaplerotic role.

A pathway-specific pattern of control of enzyme activity was originally reported by Udaka (1966): in Enterobacteriaceae, where the linear pathway operates, acetylglutamate synthase is the first committed step of the biosynthesis and is actually the target of feedback inhibition by arginine (Vyas \& Maas, 1963; Cunin et al., 
1986). In organisms using the cyclic pathway, however, the key enzyme inhibited by arginine is either $N$ acetylglutamate 5-phosphotransferase [ATP: $N$-acetylL-glutamate 5-phosphotransferase; EC 2.7.2.8; genetic symbol $\operatorname{argB}$; Udaka (1966); see Cunin et al. (1986) and Davis (1986)] or ornithine acetyltransferase itself (Van de Casteele et al., 1990); in that case, acetylglutamate synthase may (as in Pseudomonas; Haas et al., 1972) or may not (as in Thermus; Van de Casteele et al., 1990) be feedback inhibited by arginine. Two extreme thermophiles (Sulfolobus solfataricus and Thermotoga maritima), respectively using the linear and cyclic pathways, appear to be devoid of feedback inhibition (ibid.).

Some considerable time ago, the ability of the $\arg J$ enzyme to transfer acetyl groups brought about the suspicion that in the organisms using the cyclic pathway, the de novo synthesis of acetylglutamate and the transacetylation reaction may not be the exclusive attributes of two different enzymes: a brief report (Chou \& Gunsalus, 1971) even stated that in Pseudomonas putida, the enzyme specific for the synthesis of acetylglutamate was dispensable. To our knowledge, this statement has not been substantiated by further evidence but, as we shall see, it may have been premonitory of the situation existing in several organisms. Two contrasting reports appeared later on: one by Morris \& Thompson (1975), who found in Chlorella that the two activities could not be separated during partial purification, and another one by Haas et al. (1977), who reported two important observations concerning $P$. aeruginosa. In this organism, the two activities are separable by gelfiltration, and several $\arg A$ mutants could be isolated which were devoid of acetylglutamate synthase activity, displayed normal acetyltransferase activity and had an arginine-less phenotype. Acetylglutamate synthase has been studied to some extent in $P$. aeruginosa (Haas et al., 1972; Haas \& Leisinger, 1974) and in Saccharomyces cerevisiae (Wipf \& Leisinger, 1979) and found to be devoid of acetylornithine:glutamate transacetylation activity (Haas et al., 1972) The transacetylation reaction itself has not been studied extensively in any organism. Mutants defective in $\arg J$ but not in $\arg A$ have been reported in yeast (see Davis, 1986) and in Neisseria gonorrhoeae (Picard \& Dillon, 1989). Arginine auxotrophs able to grow on acetylglutamate were reported in yeast (M. Grenson, quoted in Wiame \& Dubois, 1976) but not in Neisseria. Clearly, a much less ambiguous gene-enzyme relationship had to be established before making conclusions as to the substrate specificity of the $\arg J$ enzyme and the respective roles played by $\arg A$ and $\arg J$ in different organisms.

Critical in this respect were a number of recent reports that the same short fragment of DNA from Bacillus stearothermophilus (Sakanyan et al., 1987, 1990) or from N. gonorrhoeae (Picard \& Dillon, 1989) could comple- ment both $\arg A$ and $\arg E$ (acetylornithinase) $E$. coli auxotrophs, suggesting that, in these organisms at least, a single enzyme can synthesize acetylglutamate from glutamate and either acetyl-CoA or acetylornithine as acetyl donor. In keeping with this suggestion, the shortest $B$. stearothermophilus piece of DNA able to complement $\arg A$ and $\arg E$, or $\arg A \arg E E$. coli mutants was found to be $1350 \mathrm{nt}$ (nucleotides) long (Sakanyan et al., 1992). Most recently, Martin \& Mulks (1992) cloned from Neisseria and sequenced a single gene $(\arg J)$ encoding an open reading frame (ORF) of $1218 \mathrm{nt}$ which complements both $E$. coli $\arg A$ and $\arg E$ auxotrophs.

In the present communication, we present the characterization of the $\arg J$ gene of $B$. stearothermophilus and report on the regulatory properties and partial purification of the transacetylase. We also present corresponding data concerning the adjacent $\arg B$ gene and the cognate acetylglutamate 5-phosphotransferase, the other key enzyme of the acetyl cycle of arginine biosynthesis. We discuss the metabolic significance of these data.

\section{Methods}

Bacterial strains and plasmids. These are listed in Table 1.

Media and growth conditions. E. coli strains were grown at $37^{\circ} \mathrm{C}$ in L-broth medium and in synthetic M9 (Maniatis et al., 1982) or 132 medium (Falmagne et al., 1965). Concentrations of antibiotics (in $\mu \mathrm{g} \mathrm{ml}^{-1}$ ) were: ampicillin (Ap), 100, and tetracycline hydrochloride (Tc), 30 .

DNA isolation, restriction and ligation. Plasmid DNA was isolated by the cleared lysate method according to Birnboim \& Doly (1979). Singlestranded template DNA for sequencing purposes was isolated by polyethylene glycol precipitation and phenol extraction from the supernatant of JM101 cultures infected with M13 derivatives. Restriction enzymes, T4 DNA ligase and M13 DNA were purchased from Boehringer and used according to the manufacturer's recommendations.

Transformation of bacteria. E. coli cells were made competent for transformation by $\mathrm{CaCl}_{2}$ treatment (Dagert \& Ehrlich, 1979).

Sequencing strategy. The entire $3.4 \mathrm{~kb}$ EcoRI fragment of plasmid pAVK1 was cloned into M13mp19 in one orientation. After the creation of an appropriate set of increasing unidirectional deletions according to the method of Dale et al. (1985), the sequence of the coding strand of the arg cluster of genes was established by the dideoxy chain termination method (Sanger, 1981). The 0.5 and $2.9 \mathrm{~kb} E c o$ RIPstI subfragments were respectively subcloned into $\mathrm{M} 13 \mathrm{mpl} 19$ and M13mp18 to sequence the complementary strand using a series of synthetic 20-mer oligonucleotides hybridizing to sites separated by $200 \mathrm{bp}$. Double-stranded pAVK7 DNA was also used as template to sequence the $\arg J-\arg B$ region. Ambiguities in sequence reading due to band compression were solved by substituting the analogue $\mathrm{C}^{7} \mathrm{dGTP}$ for dGTP in the sequencing mixes (Pharmacia sequencing kit).

Enzyme assays. Cells from exponential phase cultures (about $6 \times 10^{8}$ cells $\mathrm{ml}^{-1}$ ) were harvested by centrifugation $(10 \mathrm{~min}, 7000 \mathrm{~g})$ and washed in $0.9 \% \mathrm{NaCl}$. Cells were suspended in $20 \mathrm{~mm}$-potassium

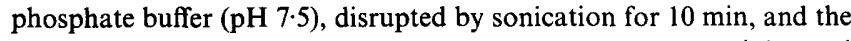
resulting extracts were centrifuged $(15 \mathrm{~min}, 20000 \mathrm{~g})$. For arginine and ornithine inhibition experiments, the crude extracts were passed through Sephadex G-25 columns equilibrated with extraction buffer. All of 
Table 1. Bacterial strains and plasmids

\begin{tabular}{|c|c|c|}
\hline Strain or plasmid & $\begin{array}{l}\text { Relevant genotype } \\
\text { or phenotype }\end{array}$ & Source or reference \\
\hline \multicolumn{3}{|l|}{ E. coli $\mathrm{K} 12$} \\
\hline JM101 & $\begin{array}{l}\text { supE thi-1 } \Delta(\text { lac-proAB }) \\
{\left[\mathrm{F}^{\prime} \text { traD36 proAB } \text { lacl }^{q} Z \Delta \mathrm{M} 15\right]}\end{array}$ & Yanisch-Perron et al. (1985) \\
\hline $\mathrm{XB} 25$ & $\mathrm{~F}^{-} \arg B$ nalA $\lambda^{-} \lambda^{\mathrm{s}} h s d R$ & S. Baumberg, University of Leeds, UK \\
\hline $\begin{array}{l}\text { XA4 } \\
\text { XA4 } \arg E\end{array}$ & $\begin{array}{l}\mathrm{F}^{-} \arg A \text { nalA } \lambda^{-} \lambda^{\mathrm{s}} h s d R \\
\text { as XA4, but } \arg E 86:: \operatorname{Tn} 10\end{array}$ & Sakanyan et al. (1992) \\
\hline $\begin{array}{l}\text { B. stearothermophilus } \\
\text { NCIB8224 }\end{array}$ & Prototroph & $\begin{array}{l}\text { All Union Collection of Microorganisms, } \\
\text { Moscow, Russia }\end{array}$ \\
\hline \multicolumn{3}{|l|}{ Plasmid } \\
\hline pAVK1 & $\mathrm{Ap}^{\mathrm{r}} \mathrm{Tc}^{\mathrm{r}} \arg ^{\prime} C J B D^{\prime}$ & Sakanyan et al. (1992) \\
\hline $\begin{array}{l}\text { pAVK7 } \\
\text { M13mp18 }\end{array}$ & $\mathrm{Ap}^{\mathrm{r}} \arg ^{\prime} C J B^{\prime}$ & \\
\hline M13mp19 & & Messing (1983) \\
\hline
\end{tabular}

these steps were performed at $0-5^{\circ} \mathrm{C}$. Enzymes were assayed at $55^{\circ} \mathrm{C}$. Inhibition studies were performed without pre-incubation.

$\mathrm{N}$-Acetylglutamate synthase and ornithine acetyltransferase were assayed as described in Van de Casteele et al. (1990), except that $15 \%$ (v/v) glycerol, $10 \mathrm{~mm}-\mathrm{MgCl}_{2}$ and $7 \mathrm{~mm}$-aminooxyacetic acid were added to the incubation mixture. Aminooxyacetic acid was added in order to reduce the transamination of glutamate in crude extracts.

$\mathrm{N}$-Acetylglutamate 5-phosphotransferase was measured by the ferric chloride method according to Van de Casteele et al. (1990).

One enzyme unit is defined as the amount of enzyme that converts $1 \mu \mathrm{mol}$ substrate to product $\mathrm{h}^{-1}$. Protein concentrations were determined by the Lowry method.

$M_{\mathrm{r}}$ determinations. $M_{\mathrm{r}}$ values of native enzymes were determined by gel-filtration on a Sephadex G-200 $(2.5 \times 30 \mathrm{~cm})$ column (eluted with $20 \mathrm{~mm}$-potassium phosphate buffer, $\mathrm{pH} \mathrm{7.5}$, at a flow rate of $6 \mathrm{ml} \mathrm{h}^{-1}$ ). The gel-filtration column was calibrated using the following standards: catalase $\left(M_{\mathrm{r}} 232000\right)$, aldolase (158000), albumin (67000), ovalbumin (43000), chymotrypsinogen A (25000) and ribonuclease A (13700). The elution volume $\left(V_{\mathrm{e}}\right)$ of each standard was determined from the absorbance at $280 \mathrm{~nm}$. N-Acetylglutamate synthase, ornithine acetyltransferase and $\mathrm{N}$-acetylglutamate 5-phosphotransferase were detected by activity measurements. The void volume $\left(V_{0}\right)$ was determined by blue dextran exclusion.

SDS-PAGE. This was done on $8-25 \%$ gradient gels in the Phast System (Pharmacia). Protein bands were visualized by staining with Coomassie brilliant blue.

\section{Results}

Sequence of B. stearothermophilus arg genes

The cloning of a $3.4 \mathrm{~kb} E c o$ RI fragment of $B$. stearothermophilus complementing $\arg A, \arg B$ and $\arg E$ auxotrophs of $E$. coli has been reported previously (Sakanyan et al., 1990). This work and a later analysis (Sakanyan et al., 1992) showed that the cloned fragment (in plasmid pAVK1) expressed activities of acetylglutamate synthase ( $\arg A$ complementation), acetylglutamate phosphotransferase ( $\arg B$ complementation) and ornithine acetyltransferase ( $\arg E$ complementation). The entire fragment has now been sequenced (Fig. 1).
Starting from the left-end border (see Fig. 2) the fragment was shown in this work to consist of (i) a sequence homologous to the carboxy-terminal part of the E. coli, $B$. subtilis and yeast $\arg C$ gene [encoding $N$-acetyl-Lglutamate 5-semialdehyde: $\mathrm{NADP}^{+}$oxidoreductase (phosphorylating); EC 1.2.1.38; see Parsot et al. (1988), Smith et al. (1990), Boonchird et al. (1991)]; (ii) an open reading frame of $1230 \mathrm{nt}$, homologous to the recently sequenced $\arg J$ gene of Neisseria [39\% identity; see Fig. 3 and Martin \& Mulks (1992)]; (iii) a complete $\arg B$ gene homologous to the cognate $E$. coli and yeast genes [ $41 \%$ identity with E. coli; Parsot et al. (1988), Boonchird et al. (1991)]; (iv) an incomplete $\arg D$ gene (encoding $N^{2}$ acetyl-L-ornithine:2-oxoglutarate aminotransferase; EC 2.6.1.11), showing $39 \%$ identity with its $E$. coli and yeast homologues (Heimberg et al., 1990). In the shorter pAVK7 plasmid (Sakanyan et al., 1990, 1992), the $\arg B$ gene is incomplete.

\section{Analysis of the sequence}

The data are compatible with the notion that the four genes are expressed as part of an operon, though substantiation of this hypothesis awaits sequencing of at least the promoter proximal part and analysis of gene transcription in the native context; these investigations are in progress and their results will be reported elsewhere. Salient features (see Fig. 1) are (i) the presence of putative ribosome binding sites proximal to $\arg J, \arg B$ and $\arg D$; (ii) an overlap between the $\arg J$ stop codon and the $\arg B$ Shine-Dalgarno site and an overlap between the $\arg B$ stop codon and the translational start of $\arg D$, suggestive of translational coupling; (iii) a codon usage (data not shown) which shows a $10 \%$ increase in the usage of $\mathrm{G}$ or $\mathrm{C}$ in the third position relative to $E$. coli.

The available (for $\arg C$ ) sequence data indicate a considerably higher percentage of identity with $B$. subtilis $(59.3 \%)$ than with $E$. coli $(39.7 \%)$ and $S$. cerevisiae 


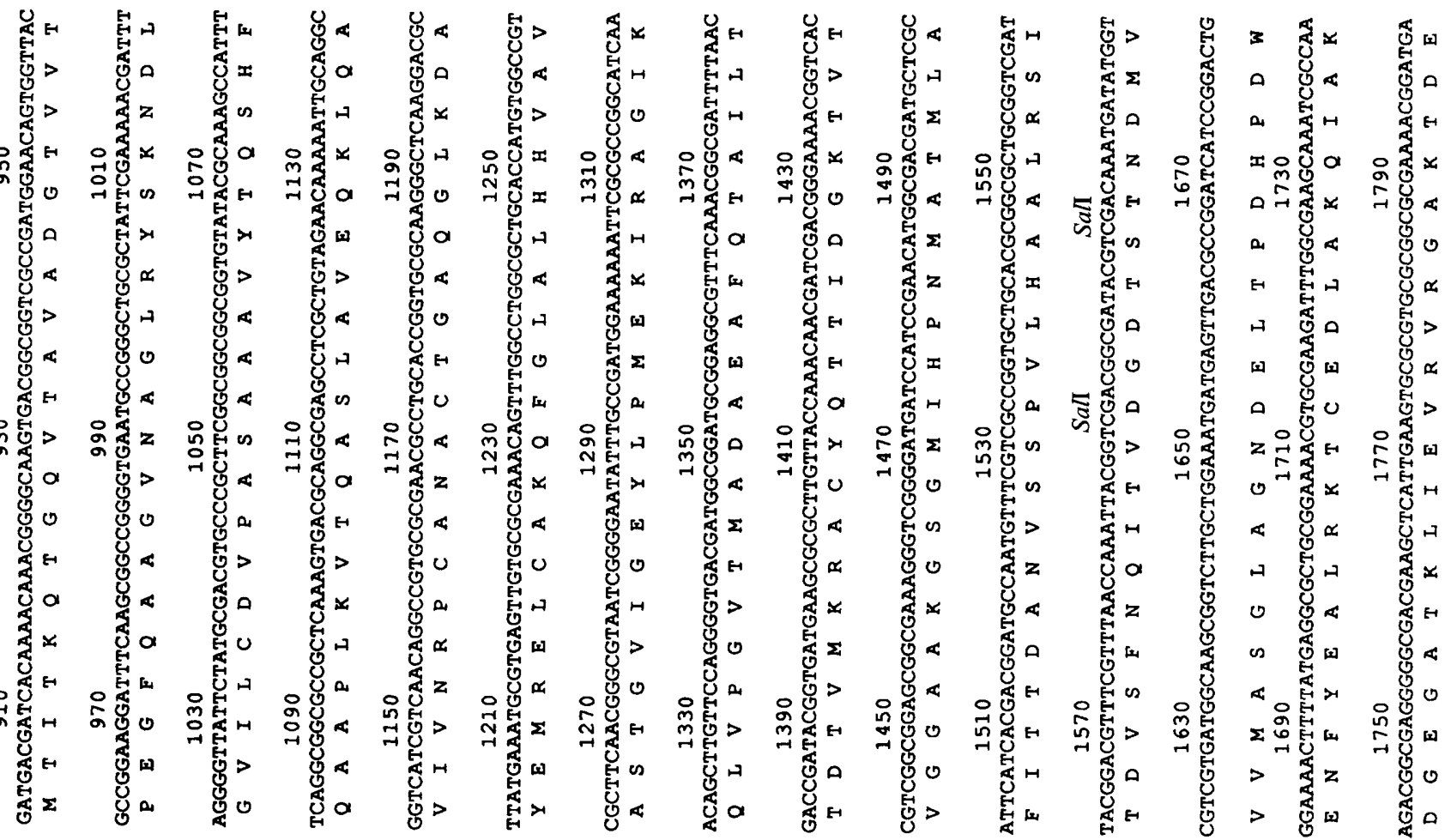

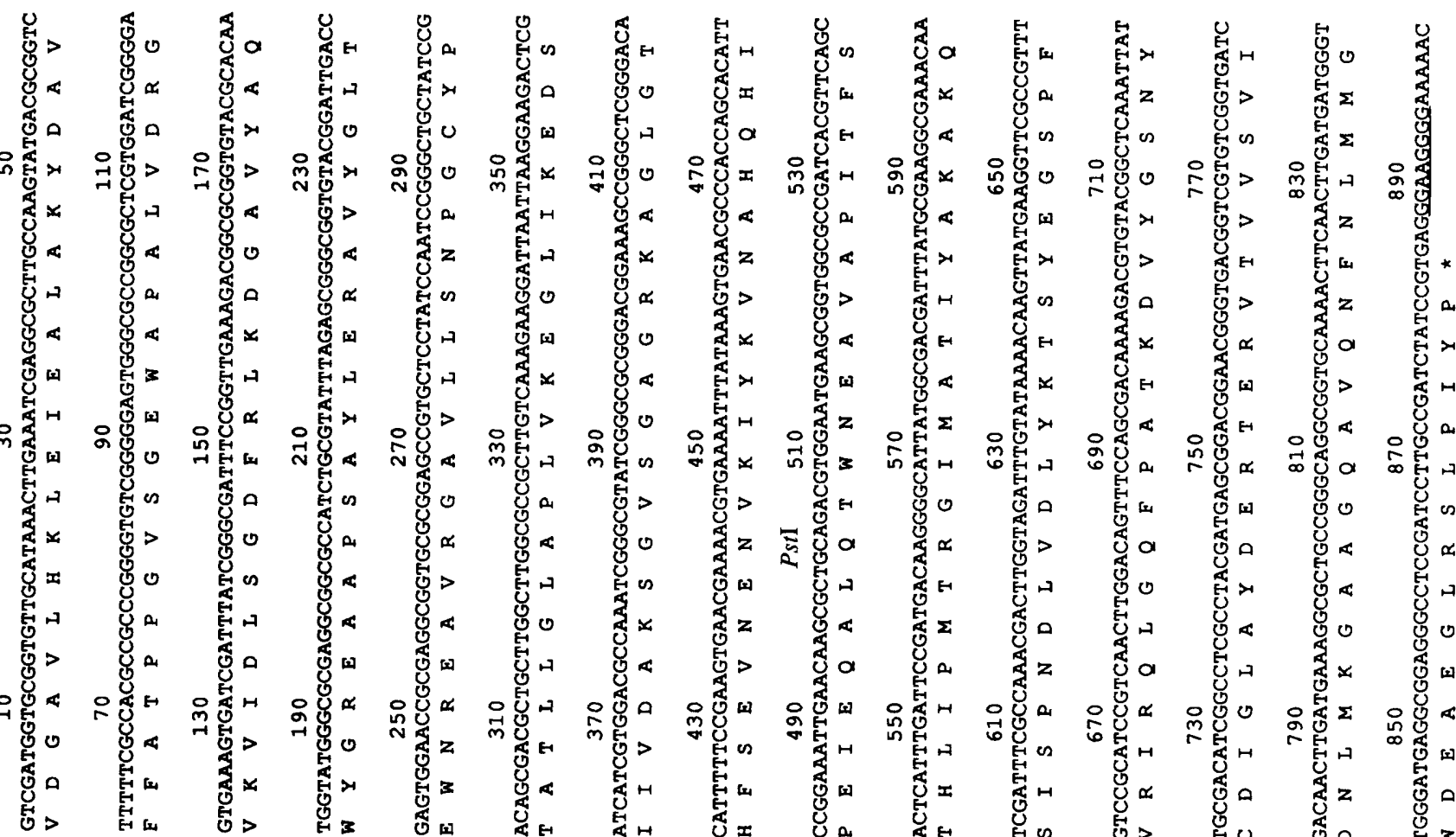



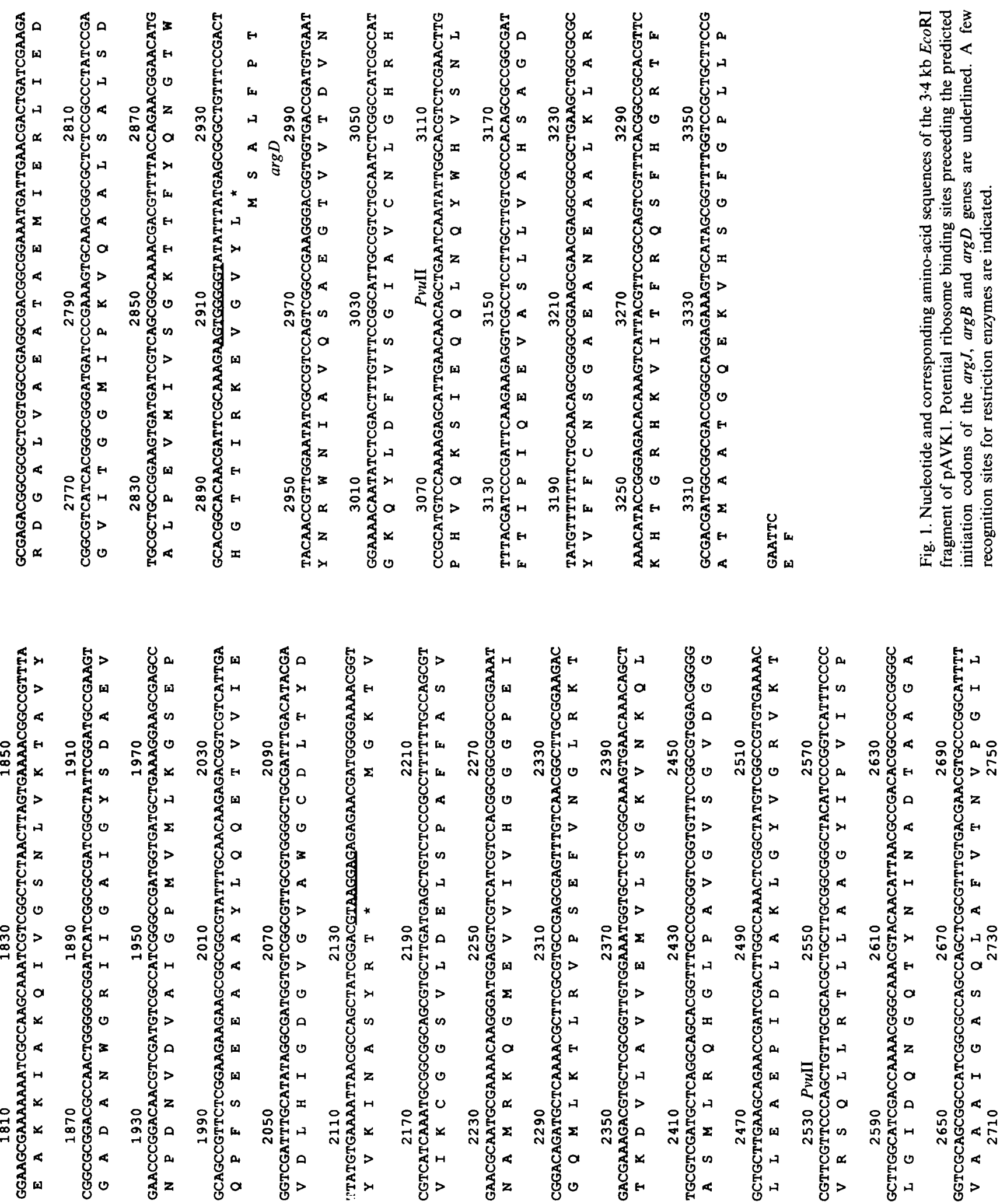


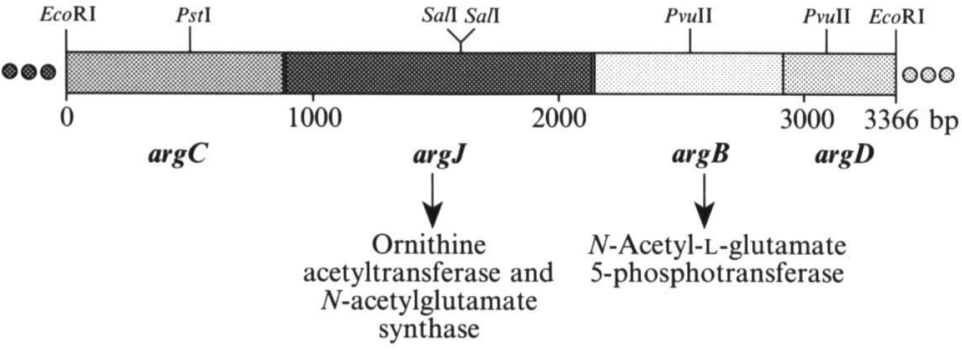

Fig. 2. Physical map and organization of the $3.4 \mathrm{~kb}$ EcoRI fragment of pAVK 1 carrying part of the $\arg$ gene cluster of $B$. stearothermophilus. The $\arg C$ (coding for $\mathrm{N}$-acetylglutamate 5-semialdehyde dehydrogenase) and $\arg D$ (coding for $N$ acetylornithine 5-aminotransferase) genes are incomplete, missing the $\mathrm{N}$-terminal and $\mathrm{C}$-terminal parts, respectively. Gene $\arg J$ encodes an active ornithine acetyltransferase that also displays $N$ acetylglutamate synthase activity; $\arg B$ encodes an intact $N$-acetylglutamate 5-phosphotransferase.
B.s.
N.g.

1

MTITKQTG

: . .

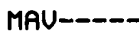

1

$50 \quad 60$

40

B.s. QUTAUADGTUUTPEGFQARGUNAGLRY-SKNDLGUILCDUPASAAAUYTQSHFQAAPLKU

N.g. NLTEKTAEQLPDIDGIALYTAQAGUKKPGHTDLTL I AUAAGSTUGAUFTTNRFCAAPUAI
10
20
30
40
50
60

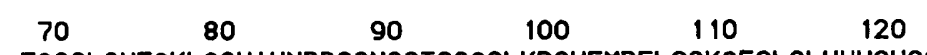

B.S. TQASLAUEQKLQAUIUNRPCANACTGAQGLKDAYEMRELCAKQFGLALHHUAUASTGUIG

N.g. AKSHLFDEDGURALUINTGNANAGTGAQGRIDALAUCARARRQIGCKPNQUNPFSTGUIL $\begin{array}{lllll}70 & 80 & 90 & 100 & 110\end{array}$

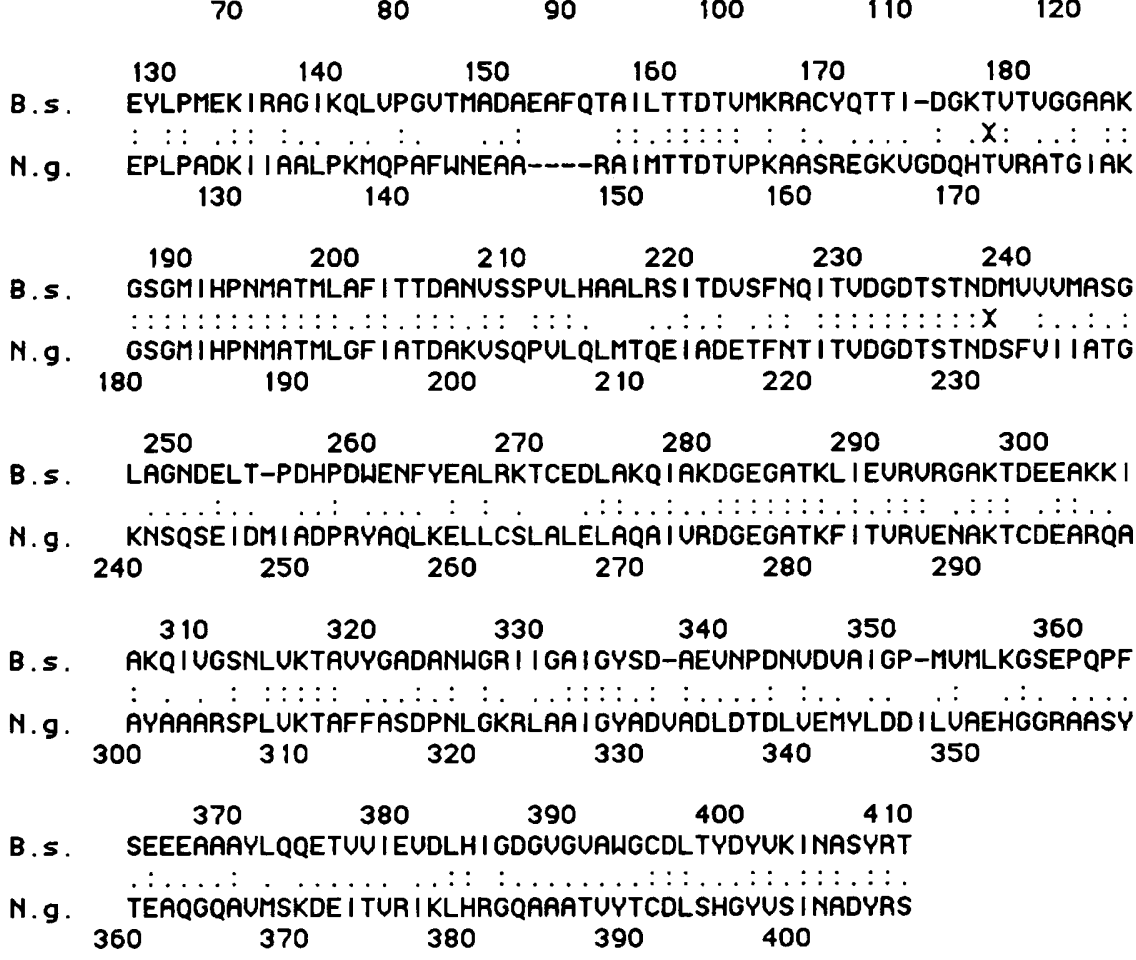

Fig. 3. Comparison of the entire amino acid sequences of the B. stearothermophilus and $N$. gonorrhoeae ornithine acetyltransferases. The sequences were compared using the FASTA computer program of Pearson \& Lipman (1988). Dashes correspond to gaps which have been introduced to align the two sequences. The symbols ' $:$ ' and ' .' indicate identical and similar residues, respectively. B.s., Bacillus stearothermophilus; N.g., Neisseria gonorrhoeae.

$(32 \cdot 2 \%)$. The truncated $\arg C$ sequence contains the conserved cysteine (nt 292 to 294) already reported by Parsot et al. (1988) in E. coli, B. subtilis and S. cerevisiae.
Using the FASTA program (Pearson \& Lipman, 1988), we could detect no significant similarity between $\arg J$ and $E$. coli $\arg A$ (previously sequenced by Brown et al., 


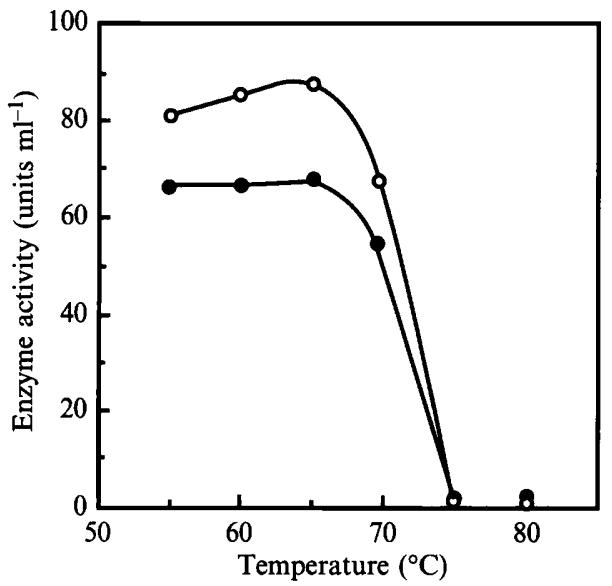

Fig. 4

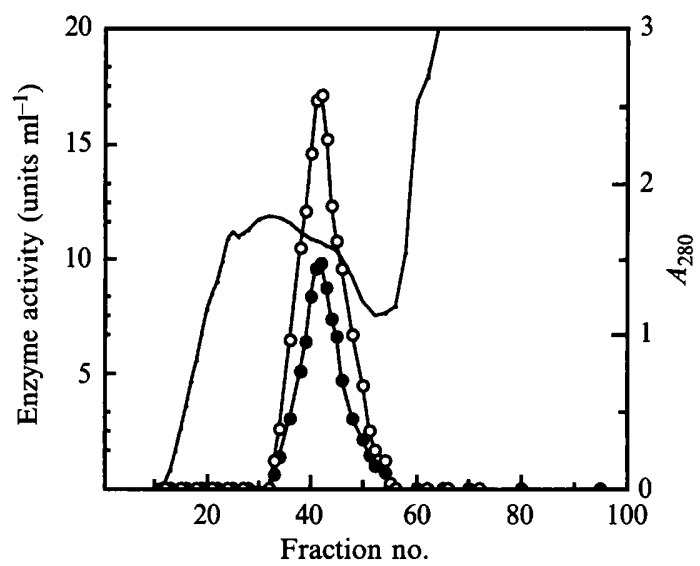

Fig. 5

Fig. 4. Thermostability of $N$-acetylglutamate synthase and ornithine acetyltransferase activity. Dialysed extract $\left(50 \mathrm{mg} \mathrm{protein} \mathrm{ml}^{-1}\right.$ in 50 mm-potassium phosphate buffer, $\mathrm{pH} 7.5$ ) of strain XA4 $\operatorname{argE}$ (pAVK7) was incubated for 20 min at various temperatures. The residual $N$-acetylglutamate synthase $(O)$ and ornithine acetyltransferase $(O)$ activities were measured under the standard assay conditions. The enzyme activity of the extract without pre-incubation or after 20 min pre-incubation at $25^{\circ} \mathrm{C}$ was 24 units $\mathrm{ml}^{-1}$ for $N$ acetylglutamate synthase and 68 units $\mathrm{ml}^{-1}$ for ornithine acetyltransferase.

Fig. 5. Sephadex G200 gel-filtration of $N$-acetylglutamate synthase and ornithine acetyltransferase activity. Crude extract (50 mg protein $\mathrm{ml}^{-1}$ in $50 \mathrm{~mm}$-potassium phosphate buffer, $\mathrm{pH} 7.5$; total vol. $25 \mathrm{ml}$ ) of strain XA4 $\arg E$ (pAVK7) was incubated for $20 \mathrm{~min}$ at $63{ }^{\circ} \mathrm{C}$. Precipitated protein was eliminated by centrifugation and the supernatant was concentrated by ultrafiltration. The heattreated extract (about $100 \mathrm{mg}$ protein in $1.5 \mathrm{ml}$ ) was applied onto the Sephadex G-200 column and eluted with $50 \mathrm{~mm}$-potassium phosphate buffer, $\mathrm{pH}$ 7.5. $\mathrm{N}$-Acetylglutamate synthase $(\mathrm{O})$ and ornithine acetyltransferase $(O)$ activities were measured in the elution fractions under the standard assay, conditions. - Absorbance at $280 \mathrm{~nm}$.

1987), as already noted by Martin \& Mulks (1992) in the case of Neisseria.

\section{Thermostability and partial purification of ornithine acetyltransferase}

E. coli $\arg A \arg E$ double mutants complemented by pAVK 7 display considerably higher specific activities of ornithine acetyltransferase and $N$-acetylglutamate synthase than B. stearothermophilus itself (Sakanyan $e t$ $a l ., 1992)$, which allowed us to investigate the enzyme more easily than in the native background and safe from interference by any additional activity that could be responsible for acetylglutamate synthesis in the mother strain. Actually, there are reasons to think that such an activity exists in extracts of $B$. stearothermophilus: data from Sakanyan et al. (1992) show that the synthesis of $N$-acetylglutamate synthase is not repressible in $B$. stearothermophilus, whereas the specific activity of ornithine acetyltransferase decreased fourfold when arginine is added to the growth medium. However, the level of $N$-acetylglutamate synthase measured in $B$. stearothermophilus extracts is low as compared to the activity observed in pAVK1 transformed $E$. coli strains. In this regard, it should be mentioned that such a low level of activity could be due to the presence in $B$. stearothermophilus extracts of an aminoacylase with broad range substrate specificity, and bearing considerable hydrolysing activity towards $N$-acetyl-Lglutamate, the product of the reaction catalysed by $N$-acetylglutamate synthase (Sakanyan et al., 1992; unpublished work).

The thermal stabilities of $N$-acetylglutamate synthase and ornithine acetyltransferase were tested in extracts of $E$. coli carrying the pAVK 7 plasmid. The results are depicted in Fig. 4, where it can be seen that both activities are inactivated by a 20 min incubation within the same short range of temperatures around $70^{\circ} \mathrm{C}$. Whereas the ornithine acetyltransferase activity remains unaffected at temperatures between 20 and $65^{\circ} \mathrm{C}$, the $\mathrm{N}$ acetylglutamate synthase activity increased threefold after pre-incubation at temperatures between 55 and $65^{\circ} \mathrm{C}$, as compared to the activity measured without preincubation or after $20 \mathrm{~min}$ pre-incubation at $25^{\circ} \mathrm{C}$. This deviation in the behaviour of the two activities is unexpected for a bifunctional enzyme. It could, for example, be due to a re-folding of the enzyme upon preincubation or, since this experiment was done with crude extract, to the destruction by heat treatment of a factor that interferes with the assay of $\mathrm{N}$-acetylglutamate synthase activity. Clearly, the interpretation of this result awaits further analysis of the behaviour of the two activities with highly purified enzyme.

However, when a heat-treated extract of $E$. coli $\mathrm{XA} 4 \arg E(\mathrm{pAVK} 7)$ was submitted to gel-filtration on Sephadex G200 (Fig. 5.), $N$-acetylglutamate synthase 
Table 2. Thermal stability of B. stearothermophilus $N$-acetylglutamate 5-phosphotransferase synthesized in E. coli

Incubation buffer was $50 \mathrm{~mm}$-potassium phosphate, $\mathrm{pH} 7.5$. Protein concentration was about $10 \mathrm{mg} \mathrm{ml}^{-1}$. The half-lives were deduced from the respective semi-log plots.

\begin{tabular}{lcc}
\hline \hline \multicolumn{1}{c}{ Protector } & $\begin{array}{c}\text { Concn } \\
(\mathrm{mM})\end{array}$ & $\begin{array}{c}\text { Half-life at } 70^{\circ} \mathrm{C} \\
(\mathrm{min})\end{array}$ \\
\hline None & - & $1 \cdot 5$ \\
MgATP & 25 & 13 \\
$N$-Acetyl-L-glutamate & 50 & 19 \\
MgATP+ & $25+$ & 183 \\
$N$-acetyl-L-glutamate & 50 & \\
\hline \hline
\end{tabular}

and ornithine acetyltransferase activities were eluted at the same position (corresponding to an $M_{\mathrm{r}}$ of 110000) and their ratio remained almost constant in the fractions that had significant activities (fraction nos 34 to 50). When a similar preparation was applied onto a DEAESepharose column and eluted with a linear gradient of

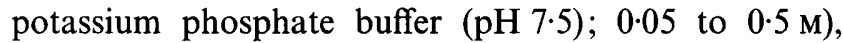
both activities co-eluted at a concentration of about 0.25 м (not shown).

\section{Feedback inhibition of $\mathrm{N}$-acetylglutamate synthase and ornithine acetyltransferase}

$\mathrm{N}$-Acetylglutamate synthase and ornithine acetyltransferase activities are but weakly inhibited by arginine, in extracts of both $E$. coli (pAVK7) and B. stearothermophilus, and the apparent $K_{\mathrm{m}}$ for acetylornithine at $10 \mathrm{~mm}$-glutamate is $0.4 \mathrm{~mm}$ (Sakanyan et al., 1992). This weak inhibition is unlikely to be physiologically significant; we found, however, that L-ornithine is a potent inhibitor of both activities. At saturating concentrations of glutamate ( $20 \mathrm{mM})$ and of either acetyl-CoA ( $2 \mathrm{mM})$ or acetylornithine $(10 \mathrm{mM})$, the apparent $K_{\mathrm{i}}$ values for ornithine were $0.02 \mathrm{~mm}$ and $0.2 \mathrm{~mm}$, respectively.

\section{Thermostability and properties of $\mathrm{N}$-acetylglutamate 5-phosphotransferase}

A very high $N$-acetylglutamate 5-phosphotransferase activity was detected in extracts of an E. coli $\arg B$ mutant (strain XB25) harbouring plasmid pAVK1 [210 units $(\mathrm{mg} \text { protein })^{-1}$, as compared to 0.3 unit (mg protein $)^{-1}$ in B. stearothermophilus extracts]. The thermostability of $\mathrm{N}$-acetylglutamate 5-phosphotransferase activity was increased in the presence of its substrates (Table 2), allowing partial purification, up to sixfold, by a heat treatment $\left(20 \mathrm{~min}\right.$ at $70^{\circ} \mathrm{C}$ in the presence of $25 \mathrm{mM}$ MgATP and $50 \mathrm{~mm}$-acetylglutamate). SDS-PAGE of such a heat-treated extract revealed a polypeptide band,

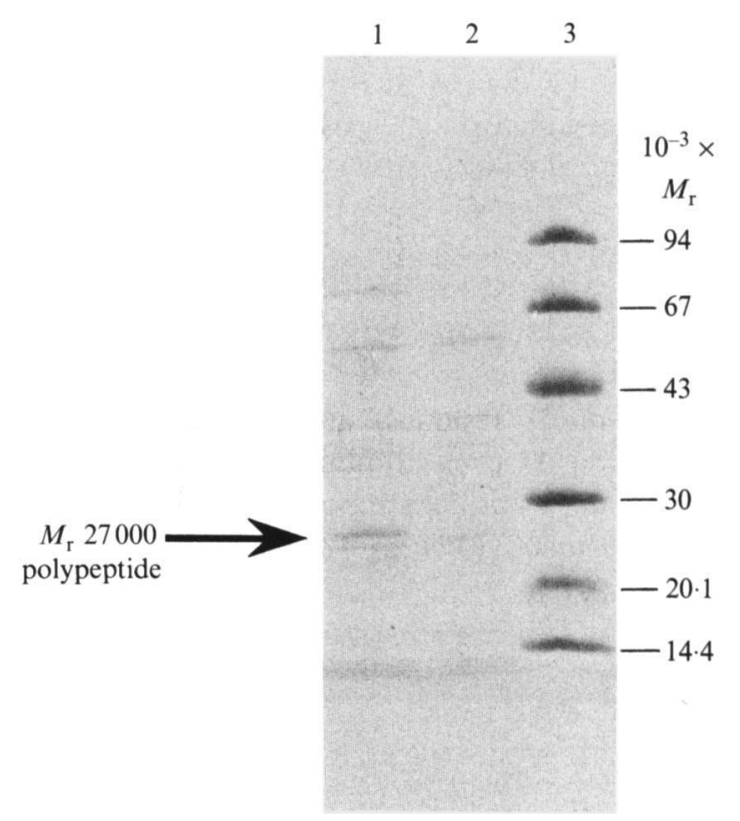

Fig. 6. SDS-PAGE of B. stearothermophilus $N$-acetylglutamate 5phosphotransferase synthesized in E. coli. Extracts (about $10 \mathrm{mg}$ protein $\mathrm{ml}^{-1}$ ) of E. coli XB25 and XB25(pAVK1) were heat-treated as stated in the text. Precipitated protein was eliminated by centrifugation and samples were heat-treated at $100^{\circ} \mathrm{C}$ for $5 \mathrm{~min}$ with an equal volume of SDS $(5 \%, \mathrm{w} / \mathrm{v})$ and $\beta$-mercaptoethanol $(10 \%, \mathrm{v} / \mathrm{v})$. Lane 1, heat-treated XB25(pAVK1) extract; lane 2, heat-treated XB25 extract; lane 3, standard proteins with the subunit $M_{\mathrm{r}}$ indicated (phosphorylase b (94000), albumin (67000), ovalbumin (43000), carbonic anhydrase (30000), trypsin inhibitor $(20100)$ and $\alpha$-lactalbumin (14400).

corresponding to an $M_{\mathrm{r}}$ of 27000 , which is absent in heattreated extract of strain XB25 devoid of plasmid pAVK1 (Fig. 6). The $M_{\mathrm{r}}$ of the enzyme, as estimated by gelfiltration on Sephadex G200, is around 29000 (in $50 \mathrm{~mm}$ potassium phosphate buffer, $\mathrm{pH} 7 \cdot 5$ ) and 55000 in the presence of $10 \mathrm{~mm}$-acetylglutamate in the elution buffer. The enzyme was not inhibited by L-ornithine or Larginine, nor by both amino acids, up to the $50 \mathrm{~mm}$ range.

\section{Discussion}

In $B$. stearothermophilus a single open reading frame (the $\arg J$ gene), originally identified by its dual complementation pattern of both $\arg A$ and $\arg E E$. coli mutants, was found to encode a transacetylase which catalyses two activities, both of them involved in the cyclic version of arginine biosynthesis: the synthesis of acetylglutamate from glutamate and acetyl-CoA and the production of ornithine by a transacetylation between acetylornithine and glutamate. The ORF is part of a cluster of functionally related genes that we have identified. It is delineated on the promoter proximal end by a sequence homologous to the $\arg C$ gene of other 
bacteria and yeast (Parsot et al., 1988; Smith et al., 1990) and on the distal site by the B. stearothermophilus $\arg B$ gene; the latter is followed by a sequence homologous to the $E$. coli and yeast genes encoding ornithine aminotransferase $(E$. coli $\arg D)$.

A bifunctional $\arg J$ gene has also been identified in $N$. gonorrhoeae by a similar dual complementation pattern (Picard \& Dillon, 1989; Martin \& Mulks, 1992). This gene and the $B$. stearothermophilus cognate sequence share $39 \%$ identical residues, a clear indication of homology; therefore, even though $\mathrm{N}$-acetylglutamate synthase assays have not been reported for the reaction catalysed by the argJ protein in Neisseria, there is little doubt that the two organisms use very similar enzymes. Preliminary evidence from this laboratory (M. Baetens, unpublished) indicates that Thermus aquaticus and $T$. thermophilus also have a bifunctional argJ gene.

Ornithine, and not arginine, appears to be the significant metabolite controlling the enzyme, the $\mathrm{N}$ acetylglutamate synthase reaction being by far the most sensitive one: a $0.02 \mathrm{~mm}$ apparent $K_{\mathrm{i}}$ with respect to $0.2 \mathrm{mM}$ for the ornithine acetyltransferase reaction. $B$. stearothermophilus has an inducible arginase, converting arginine into ornithine and urea (M. Demarez \& $\mathrm{C}$. Legrain, unpublished). It is therefore reasonable to assume that excess arginine leads to the build-up of an ornithine pool able to inhibit $\arg J$ activity; this remains to be demonstrated, however. On the other hand, acetylglutamate phosphotransferase is not feedbackinhibited in B. stearothermophilus, in contrast to many organisms endowed with an acetyl cycle. In terms of metabolic efficiency, this would be understandable inasmuch as the control exerted by ornithine on the bifunctional $\arg J$ enzyme is efficient enough to curtail the flow of arginine. Considering that the apparent $K_{\mathrm{i}}$ values mentioned above were obtained in the presence of saturating concentrations of substrates, this is not an unreasonable assumption.

At first sight, the bifunctionality of the $\arg J$ protein would appear to make an $\arg A$ function superfluous even though there are genetic arguments from Neisseria (the complementation of $\arg A E$. coli mutants by DNA unlinked to $\arg J$; Martin \& Mulks, 1992) and enzyme data for B. stearothermophilus (Sakanyan et al., 1992) that these organisms possess such a function. However, there is presently no evidence that the $N$-acetylglutamate synthase activity of the transacetylase is actually used in vivo; this remains an important issue. Presently, $P$. aeruginosa is the only organism endowed with a cyclic pathway where the $\arg A$ function has been well enough characterized to comment further on this problem: the $\arg A$ enzyme does not use acetylornithine as substrate, $\arg A$ mutants have an arginine-less phenotype, they display no $\mathrm{N}$-acetylglutamate synthase activity but normal ornithine acetyltransferase activity (Haas \& Leisinger, 1974; Haas et al., 1977). In P. aeruginosa, therefore, one would tend to conclude that $\arg J$ is not bifunctional. To further substantiate that statement requires characterization of the $\arg J$ gene and of the cognate protein, however. It may be noted here that in $B$. subtilis a particular subfragment of the cluster of six arg genes cloned by Mountain et al. (1986) complements $\arg E$ mutants but not $\arg A$ mutants of $E$. coli. Now that it is known that $B$. subtilis, like $B$. licheniformis and $B$. stearothermophilus, uses the cyclic pathway of arginine biosynthesis (Sakanyan et al., 1992), this pattern could be explained if the complementing fragment contained a truncated $\arg J$ gene having lost the $N$-acetylglutamate synthase function, creating a situation at least superficially reminiscent of the pattern described above for $P$. aeruginosa. Comparing and manipulating cloned arg $J$ genes will settle the matter.

It is striking that the argJ genes from Neisseria and Bacillus, despite their $N$-acetylglutamate synthase function, display no recognizable homology with the $\arg A$ gene from $E$. coli. Less surprising is the absence of homology with $\arg E$ which, on the other hand, has been recognized as probably being homologous to the genes for a carboxypeptidase of Pseudomonas and for the succinyldiaminopimelate desuccinylase of $E$. coli (Boyen et al., 1992; Meinnel et al., 1992). No sign of homology can be detected either between $\arg J$ and the $\arg E$ complementing sequence cloned from Leptospira, the origin of which remains a mystery (Zuerner \& Charon, 1988).

We estimate the $M_{\mathrm{r}}$ of the native transacetylase as 110000 on the basis of gel-filtration. This suggests that the protein is a dimer; indeed, the predicted $M_{\mathrm{r}}$ of the encoded $\arg J$ polypeptide is 43349 , which is in keeping with the size of the subunit estimated by Martin \& Mulks (1992) by expressing Neisseria argJ in minicells. As estimated by gel-filtration in the presence of $N$ acetylglutamate and $\mathrm{MgATP}$, the $\arg B$ protein has a $M_{\mathrm{r}}$ of 55000, and could therefore be a dimer (the predicted $M_{\mathrm{r}}$ of the encoded $\arg B$ polypeptide is 26918 , close to the value found in $E$. coli). The sequence indicates that the $\arg B$ protein is not produced from a precursor common to $\arg B$ and $\arg C$ as in yeast (Boonchird et al., 1991). It will be interesting to see whether this pattern also prevails in more extreme thermophiles, considering the thermolability of acetylglutamate phosphate. At any rate, some form of channeling for this molecule would be expected at higher temperatures.

We thank N. Huysveld and M. Demarez for excellent technical assistance, D. Gigot for oligonucleotide synthesis and A. Boyen and A. Feller for assistance in computer analysis. This work was supported by the Belgian Fund for Joint Research (contracts 2.9003.88 and 2.9007.92), by a Concerted Research Action between the French and 
Flemish Communities and the cognate Free Universities of Brussels, by the Flemish Action Program for Biotechnology and by the Armenian Ministry of Economics. V.S. gratefully acknowledges the financial support of the Belgian National Foundation for Scientific Research for his visit to Belgium.

\section{References}

BIRnBoim, H. C. \& Doly, J. (1979). A rapid alkaline extraction procedure for screening recombinant DNA. Nucleic Acids Research 7, 1513-1523.

BoONCHIRD, C., MessenguY, F. \& DuBois, E. (1991). Characterization of the yeast $A R G$ 5,6 gene: determination of the nucleotide sequence, analysis of the control region and of ARG 5,6 transcript. Molecular and General Genetics 226, 154-166.

Boyen, A., Charlier, D., Charlier, J., Sakanyan, V., Mett, I. \& GlaNSDORFF, N. (1992). Acetylornithine deacetylase, succinyldiaminopimelate desuccinylase and carboxypeptidase G2 are evolutionary related. Gene 116, 1-6.

Brown, K., Finch, P. W., Hickson, I. D. \& Emmerson, P. T. (1987). Complete nucleotide sequence of the Escherichia coli $\arg A$ gene. Nucleic Acids Research 15, 10586.

Chou, I. N. \& Gunsalus I. C. (1971). Arginine biosynthesis in Pseudomonas putida. Bacteriological Proceedings 140, 162.

Cunin, R., Glansdorff, N., Piérard, A. \& Stalon, V. (1986). Biosynthesis and metabolism of arginine in bacteria. Microbiological Reviews 50, 314-352.

DAGERT, M. \& EHRLICH, S. D. (1979). Prolonged incubation in calcium chloride improves the competence of E. coli cells. Gene 6, 23-28.

Dale, R. M. K., McClure, B. A. \& Mouchins, J. P. (1985). A rapid single-stranded cloning strategy for producing a sequential series of overlapping clones for use in DNA sequencing: application to sequencing the corn mitochondrial 18S RNA. Plasmid 13, 31-40.

DAvIS, R. H. (1986). Compartmental and regulatory mechanisms in the arginine pathways of Neurospora crassa and Saccharomyces cerevisiae. Microbiological Reviews 50, 280-313

Falmagne, P., Vanderwinkel, E. \& Wiame, J. M. (1965). Mise en évidence de deux malate synthétases chez Escherichia coli. Biochimica et Biophysica Acta 99, 246-258.

HAAS, D. \& LeISINGER, T. (1974) Multiple control of $\mathrm{N}$-acetylglutamate synthetase from Pseudomonas aeruginosa: synergistic inhibition by acetylglutamate and polyamines. Biophysical and Biochemical Research Communications 60, 42-47.

HAAS, D., KURER, V. \& LeISINGER, T. (1972). N-Acetylglutamate synthetase of Pseudomonas aeruginosa. An assay in vitro and feedback inhibition by arginine. European Journal of Biochemistry 31, 290-295.

HaAs, D., Holloway, B. W., Schamböck, A. \& Leisinger, T. (1977). The genetic organization of arginine biosynthesis in Pseudomonas aeruginosa. Molecular and General Genetics 154, 7-22.

Heimberg, H., Boyen, A., Crabeel, M. \& Glansdorff, N. (1990). Escherichia coli and Saccharomyces cerevisiae acetylornithine aminotransferases: evolutionary relationship with ornithine aminotransferases. Gene 90, 69-78.

Maniatis, T., Fritsch, E. F. \& Sambrook, J. (1982). Molecular Cloning. A Laboratory Manual. Cold Spring Harbor, NY: Cold Spring Harbor Laboratory.

MARTin, P. R. \& MulKs, M. H. (1992). Sequence analysis and complementation studies of the argJ gene encoding ornithine acetyltransferase from Neisseria gonorrhoeae. Journal of Bacteriology 174, 2694-2701.

Meinnel, T., Schmitt, E., Mechulam, Y. \& Blanquet, S. (1992). Structural and biochemical characterization of the Escherichia coli $\arg E$ gene product. Journal of Bacteriology 174, 2323-2337.
Messing, J. (1983). New M13 vectors for cloning. Methods in Enzymology 101, 20-78.

MorRis, C. J. \& ThOMPSON, J. F. (1975). Acetyl coenzyme A-glutamate acetyltransferase and $N^{2}$-acetylornithine acetyltransferase of Chlorella. Plant Physiology 55, 960-967.

Mountain, A., McChesney, J., Smith, M. C. M. \& Baumberg, S. (1986). Gene sequence encoding early enzymes of arginine synthesis within a cluster in Bacillus subtilis, as revealed by cloning in Escherichia coli. Journal of Bacteriology 165, 1026-1028.

Parsot, C., Boyen, A., Cohen, G. N. \& Glansdorff, N. (1988). Nucleotide sequence of Escherichia coli $\arg B$ and $\arg C$ genes: comparison of $N$-acetylglutamate kinase and $N$-acetylglutamate- $\gamma$ semialdehyde dehydrogenase with homologous and analogous enzymes. Gene 68, 275-283.

Pearson, W. R. \& Lipman, D. J. (1988). Improved tools for biological sequence comparison. Proceedings of the National Academy of Sciences of the United States of America 85, 2444-2448.

PiCARD, F. J. \& Dillon J. R. (1989). Cloning and organization of seven arginine biosynthesis genes from Neisseria gonorrhoeae. Journal of Bacteriology 171, 1644-1651.

Sakanyan, V. A., Hovsepyan, A. S., Mett, I. L., Kochikyan, A. V. \& Petrosyan, P. K. (1990). Molecular cloning and structural-functional analysis of the arginine biosynthesis genes of the thermophilic bacterium Bacillus stearothermophilus. Genetika (USSR) 26, 1915-1925.

Sakanyan, V. A., Mett, I. L., Nersisyan, A. A., Hovsepyan, A. S., Kochikyan, A. V., Petrosyan, P. K. \& Alikhanian, Z. R. (1987). Molecular organization and regulation of arginine biosynthesis genes of Bacillus. Abstract of the $V^{\text {th }}$ Congress of All-Union Society for Genetics and Selection, Moscow.

Sakanyan, V., Kochikyan, A., Mett, I., Legrain, C., Charlier, D., Pífard, A. \& GlansDorfF, N. (1992). A re-examination of the pathway for ornithine biosynthesis in a thermophilic and two mesophilic Bacillus species. Journal of General Microbiology 138, $125-130$.

SANGER, F. (1981). Determination of nucleotide sequences in DNA. Science 214, 1205-1210.

Smith, M. C. M., Mountain, A. \& Baumberg, S. (1990). Nucleotide sequence of Bacillus subtilis arg $C$ gene encoding $N$-acetylglutamategamma-semialdehyde dehydrogenase. Nucleic Acids Research 18, 4595.

UdAKA, S. (1966). Pathway-specific pattern of control of arginine biosynthesis in bacteria. Journal of Bacteriology 91, 617-621.

Van de Casteele, M. Demarez, M., Legrain, C., GlansdorfF, N. \& PIÉRARD, A. (1990). Pathways of arginine biosynthesis in extreme thermophilic archaeo- and eubacteria. Journal of General Microbiology 136, 1177-1183.

VYAS, S. \& MAAS, W. K. (1963). Feedback inhibition of acetylglutamate synthetase by arginine in Escherichia coli. Archives of Biochemistry and Biophysics 100, 542-546.

WiAmE, J. M. \& DuBois, E. L. (1976). The regulation of enzyme synthesis in arginine metabolism of Saccharomyces cerevisiae. In Reprint from the IInd International Symposium on the Genetics of Industrial Microorganisms, Sheffield, 1974, pp. 391-406. London: Academic Press.

WIPF, B. \& LeISINGER, T. (1979). Regulation of activity and synthesis of $N$-acetylglutamate synthase from Saccharomyces cerevisiae. Journal of Bacteriology 140, 874-880.

YanisCh-Perron, C., VieiRA, J. \& Messing, J. (1985). Improved M13 phage vectors and host strains: nucleotide sequences of the M13mp18 and pUC19 vectors. Gene 33, 103-119.

Zuerner, R. L. \& ChARON, N. W. (1988). Nucleotide sequence analysis of a gene from Leptospira biflexa serovar patoc which complements an $\arg E$ defect in Escherichia coli. Journal of Bacteriology 170, $4548-4554$. 